Article

\title{
Research of the Effect of Tourism Economic Contact on the Efficiency of the Tourism Industry
}

\author{
Yongquan $\mathrm{Li}^{1}$, Rui $\mathrm{Li}^{2, *}$, Wenqi Ruan ${ }^{2}$ and Chih-Hsing Liu ${ }^{3,4, *(\mathbb{C})}$ \\ 1 Research Center of Tourism and Hospitality Management, College of Tourism, Huaqiao University, \\ Quanzhou 362021, Fujian, China; lyqax@hqu.edu.cn \\ 2 College of Tourism, Huaqiao University, Quanzhou 362021, Fujian, China; 1601108003@stu.hqu.edu.cn \\ 3 Department of Tourism Management, National Kaohsiung University of Science and Technology, \\ Gaoxiong 80778, Taiwan \\ 4 Leisure \& Recreation Administration Department, Ming Chuan University, Taipei 33348, Taiwan \\ * Correspondence: 18013121013@stu.hqu.edu.cn (R.L.); samliu@nkust.edu.tw (C.-H.L.)
}

Received: 11 June 2020; Accepted: 7 July 2020; Published: 14 July 2020

check for updates

\begin{abstract}
Following regional tourism cooperation, the promotion of balanced sustainable development has begun to play a vital role in the tourism industry. Using the West Coast of the Strait urban agglomeration, China, as an example, this study uses a data envelopment analysis (DEA) to analyzes the nonlinear relationship between tourism economic contact intensity and tourism industry efficiency by constructing a mixed effect model. The results show the following: (1) In the early stage of regional tourism cooperation, the efficiency of the tourism industry will decrease with an increase in the intensity of tourism economic contact. As regional cooperation tends towards a stable stage, the efficiency of the tourism industry will continue to increase with the strengthening of the intensity of tourism economic contact. (2) The regional economic level harms the efficiency of the tourism industry. The urbanization level has a positive effect on the efficiency of the tourism industry. (3) The level of opening up and transportation development in the region will not only bring tourism resources or tourists, but also lead them to flow out. They have no significant impacts on the efficiency of the tourism industry.
\end{abstract}

Keywords: tourism contact; tourism efficiency; U-shaped; DEA

\section{Introduction}

The tourism industry has gradually become one of the most promising and fastest-growing fields in global economic development, and is an important part of a country's socioeconomic system [1]. China is the largest tourism market and international tourism consumption country in the world. As the strategic pillar industry of its national economic development, the tourism industry has been fully integrated into its national development strategy. According to the China tourism academy, China's tourism industry contributed $11.05 \%$ to GDP and $10.31 \%$ to national employment in 2019 [2]. With the rapid development of traffic and information technology levels, the time and distance between regions decreased, and the inter-regional tourism economy is more closely linked [3]. Tourism cooperation has been strengthened and contributes to the rapid and stable development of the tourism industry [3]. The strengthening of tourism economic connections has significantly strengthened the mobility of related tourism elements between regions, and the spatial configuration and integration form of tourism elements are constantly evolving [4]. These effects are beneficial to the optimization of the spatial structure of the tourism economy to a certain extent, and further enhance the economic growth of regional tourism [5]—which has a crucial impact on the high-quality and sustainable development of tourism. Therefore, research on the relationship between tourism 
economic contact and the high-quality development of tourism needs urgent attention against the background of reduced distance, time and flow space.

Currently, there are few studies on the impact of tourism economic contact on the efficiency of the tourism industry. As the primary method of linking tourist destinations, tourism economic contact has received more attention from academic circles. Domestic and foreign studies mainly focus on the spatial differences, structure, characteristics, and evolution of tourism economic contact-including the exploration of various scales, such as province, region, economic zone and city [6-8]. Many scholars have also discussed the coupling degree and influence mechanism of tourism economic contact, including the coupling among traffic accessibility, tourism flow and tourism economic contact $[9,10]$. Some scholars have explored the impact of tourism economic contact on the high-quality development of tourism from the outside. They have found that the enhancement of tourism economic contact can promote the flow and rational allocation of tourism resources [11], and that the benign flow and interaction of tourism elements are conducive to optimizing the structure of the tourism economic network [12]. This improves the efficiency of economic contact, thus promoting the rapid growth and high-quality development of the tourism economy and enhancing the comprehensive benefits of the tourism economy [13]. The efficiency of the tourism industry represents the economic benefits that a region can obtain after investing a certain cost, which can be used to measure the quality of tourism economic development in a region [14]. The efficiency of the tourism industry also reflects the perspective that tourism economic contact has a certain impact on the efficiency of the tourism industry, but the direct impact of tourism economic contact on the efficiency of the tourism industry is rarely studied. Current research rarely considers whether tourism economic contact and the efficiency of the tourism industry have a strong spatial dependence and correlation. Tourism economic contact promotes the spatial agglomeration and diffusion of tourism elements, which is conducive to strengthening regional tourism cooperation and further enhancing the efficiency of the tourism industry. Therefore, based on the background of the rapid development of the economy and tourism and the continuous enhancement of tourism economic contact between regions, this study mainly explores the following questions: (1) How does the strength of tourism economic contact affect the efficiency of the tourism industry? (2) What other factors are involved in the relationship? (3) How does the strength of tourism economic contact affect the efficiency of the tourism industry? (4) What are the influencing factors? These problems have not been effectively solved, and need to be further explored.

This study uses the West Coast of the Strait urban agglomeration, China, as the research case, and uses the gravity correction model to measure the strength of tourism economic contact. It also uses the data envelopment analysis (DEA) method to measure the efficiency of the tourism industry, and adds the five control variables of the regional economic development level, urbanization level, industrial structure, the level of opening up to the outside world and the level of traffic development. This study analyzes the effect of the tourism economic contact intensity on the efficiency of the tourism industry by constructing an econometric model. First, the strength of tourism economic contact measured by the gravity correction model has a boundary property, so that it can analyze the influence of tourism economic contact on the efficiency of the tourism industry in a region. Second, the data envelopment analysis (DEA) method is used to address more complex input-output factors in the tourism industry, which can provide a better effect of relative efficiency. Finally, constructing an econometric model to analyze the nonlinear influence of the tourism economic contact strength on the efficiency of the tourism industry can deeply analyze the difference in its influence and explore the influence of control variables on the efficiency of the tourism industry, allowing the development of targeted development strategies for the regional tourism industry. The purpose of this study is to provide theoretical guidance on the effect of regional tourism economic contact and the improvement of tourism industry efficiency and to provide practical inspiration for promoting regional tourism cooperation, improving the efficiency of the tourism industry and enhancing tourism competitiveness. 


\section{Literature Review}

Scholars have previously performed relevant studies on the economic contact of tourism. Christaller (1964) explored the positive significance of cities on their direct hinterland economy based on the "Central Place Theory" proposed by the German geographer Christaller and the economist August in the 1930s and 1940s [15]. With the rapid development of industrialization and the trend of urban agglomerations gradually spreading along the outer edge, the research scope of tourism economic contact has also expanded from cities to urban agglomerations. The Spatial Interaction theory proposed by Ullman laid the foundation for subsequent research on the tourism economic contact between cities [16], and the gradually developed Core-brim and Space Spread theories have also provided certain theoretical support for the deepening of relevant research [17]. Relevant research has mainly focused on the spatial structure and the characteristic of economic contact, the correlation between economic contact and transportation, the measurement of urban agglomeration tourism economic contact, the economic contact and spatial fractal, the spatial structure and spatial development model of tourism economic contact, the coupling development of tourism economic contact, etc. Scholars have made efforts in different aspects of these studies. Garza (1999) explored the evolution of the spatial structure of the economic contact between urban agglomerations [18]. Dredge (1999) explored tourism flow and a spatial structure model [19]. Cao, Wu and other scholars used the Yangtze River Delta City Region as a research object and constructed a spatial model of tourism economic contact from the perspective of time-distance [20]. Yang and other scholars explored the spatial structure of tourism economic contact in the Beijing-Tianjin-Hebei-Xiong'an Region based on a gravity model and the social network analysis (SNA) method [21]. Lis (2001) and other scholars conducted in-depth studies on the spatial accessibility of urban agglomerations [22]. Ni and Liao analyzed the characteristics of tourism economic contact in the provincial capitals of China under the influence of a high-speed railway [23].

There are few studies on the direct impact of tourism economic contact on the development of tourism, and most existing studies have explored the impact of tourism economic contact on the development of the tourism industry from the outside. Simmons (1994) proposed the relationship between local residents' participation in community tourism development and tourism development. Dwyer, Forsyth and Spurr (2004) explored the economic benefits of the tourism economic industry and proposed CEG model as a potential model to analyze the economic impact of tourism. Marrocu and Paci (2011) explored the relationship between new information, tourism flow and product efficiency in Europe and proposed that tourism could help improve regional efficiency. Jiang (2017) proposed that with the rapid development of the economy and the Internet, regional links will become closer and more efficient, which will promote the rapid expansion of the tourism market [24]. Chen et al. (2009) and Gavilán et al. (2015) discussed the impact of tourism cooperation and the spatial structure of the tourism economy on the development of the tourism industry [25,26]. Ye and Wang (2019) and other scholars believe that the improvement of regional accessibility has a connection with the tourism economy, promotes scientific and rational allocation, integrates and optimizes various elements in a regional tourism system, drives the improvement of the efficiency of tourism spatial cooperation, and ultimately enables the common and high-quality development of a regional tourism economy [10]. $\mathrm{Liu}, \mathrm{Lu}(2015)$ and other scholars have posited that the development efficiency and growth quality of the tourism industry are the primary conditions for tourism sustainable development. They argue that strengthening the exchange and cooperation of key elements of regional tourism development (such as information, technology and talents) will be beneficial to realize the regional sharing of tourism elements, and can effectively improve the overall efficiency of tourism industry development [27].

In summary, current domestic and foreign studies on tourism economic contact mainly analyze the preformation causes and forward-looking factors of tourism economic contact from multiple perspectives, such as characteristics, differences, spatial structure, development model and coupling degree. Less attention is paid to the backward effect of tourism economic contact. Some studies analyze the impact of tourism economic contact on tourism development from the outside, while few studies focus on the direct relationship between tourism economic contact and tourism industry 
efficiency. Against the background of economic globalization and regional integration, regional cooperation has gradually become an important trend in tourism development. It is increasingly important to strengthen tourism economic contact between regions [28,29], with the ultimate goal of achieving efficient development of regional tourism. Therefore, it is of great academic value and practical significance to explore the influence of tourism economic contact on the efficiency of the tourism industry.

\section{Research Design}

\subsection{Study Areas}

This study takes 20 cities in the West Coast of the Strait urban agglomeration, China, as the study site, and Figure 1 indicates the 20 cities it contains. The West Coast of the Strait urban agglomeration, also known as the West Strait Economic Zone, is located in Southeast China. According to the Coordinated Development Plan for the Cities Group on the West Bank of the Straits, the city group is a national-level city cluster with Fuzhou, Xiamen, Quanzhou, Shantou and Wenzhou as the core of the five major central cities, with a total of 20 prefecture-level cities. With a total land area of 270,000 square kilometers and a regional GDP of more than 587.2345 billion yuan in 2018, it is one of the most dynamic areas in China, with a high level of transportation development. The tourism resources of the 20 cities in the West Coast of the Strait urban agglomeration are extremely rich and highly complementary, and it is one of the most mature regions for tourism development in China.

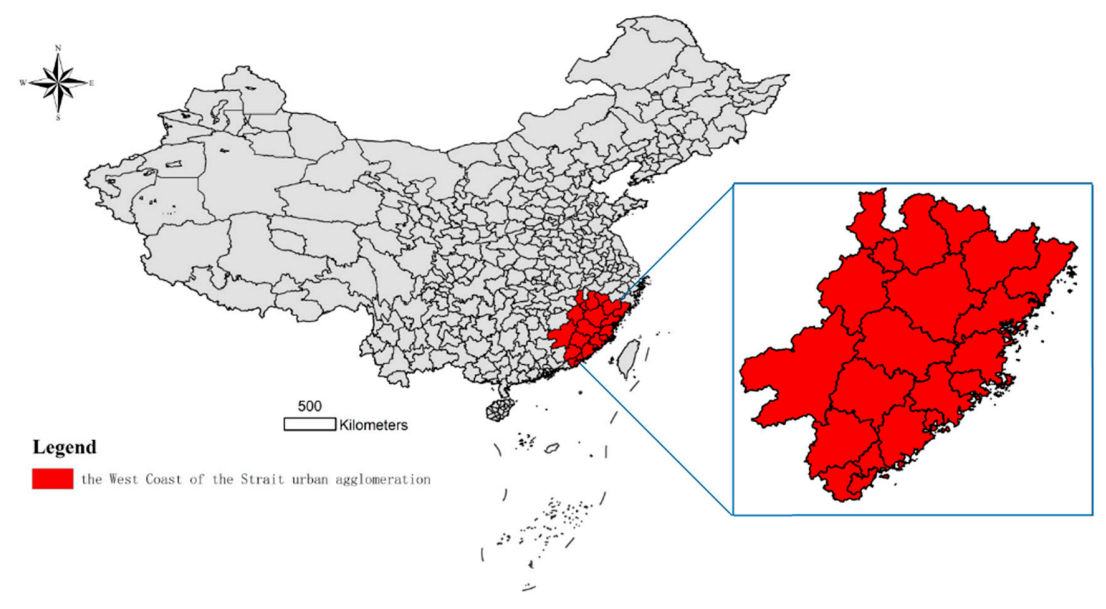

Figure 1. Study site map.

\subsection{Research Methods}

\subsubsection{Gravity Correction Model}

Various elements between regions are constantly flowing and exchanging, with the cities as carriers. Therefore, this study uses a gravity correction model to measure the intensity of tourism economic contact in the West Coast of the Strait urban agglomeration [20]. Due to the inequality between the intensity of tourism economic contact in various regions and to show the directivity of the intensity of tourism economic contact, the proportion of tourism resource endowment stakes is the sum of the tourism resource endowments between two associated cities. This study measures the amount of tourism economic contact for a city by summing the amount of tourism economic contact between the city and all other cities in the region [30]. The relevant formulas are as follows:

$$
P_{i j}=m_{i j} \frac{\sqrt[3]{T_{i} V_{i} W_{i}} \sqrt[3]{T_{j} V_{j} W_{j}}}{C^{2}}
$$




$$
\begin{aligned}
m_{i j} & =\frac{S_{i}}{S_{i}+S_{j}} \\
G_{i j} & =\sum P_{i j}
\end{aligned}
$$

In formula (1), $P_{i j}$ represents the attraction of tourism between city $i$ and city $j$; and also represents the strength of tourism economic contact between city $i$ and city $j, T_{i}$ and $T_{j}$ represent the total number of tourists in cities $i$ and $j$ that year, respectively; $V_{i}$ and $V_{j}$ represent the total tourism revenue of the two cities in that year; $W_{i}$ and $W_{j}$ are the total GDP of the two cities that year; and $C_{i j}$ represents the linear spatial distance between the two cities. In formula (2), $m_{i j}$ is the gravitational coefficient, which uses the numbers of $4 \mathrm{~A}$ and $5 \mathrm{~A}$ scenic locations as a measurement index, and $S_{i}$ and $S_{j}$ represent the total number of $4 \mathrm{~A}$ and $5 \mathrm{~A}$ scenic locations in the two cities that year, respectively. In formula (3), $G_{i j}$ represents the amount of tourism economic contact of city $i$.

\subsubsection{Data Envelopment Analysis (DEA) Approach}

Data envelopment analysis (DEA) is an effective method to analyze the multi-input and multi-output of the decision-making units (DMU) and to compare their relative efficiency and benefit [31]. As a typical basic model in DEA, the BCC model is widely used in analyzing tourism efficiency. The model decomposes technical efficiency (TE) into pure technical efficiency (PTE) and scale efficiency (SE), that is, technical efficiency $=$ pure technical efficiency $\times$ scale efficiency. Pure technical efficiency refers to the technical efficiency obtained by measuring the resource allocation efficiency at the current technical level on the basis of the variable scale benefit; scale efficiency means that on the basis of a constant control system and the management and technical levels, the difference between the current scale and the optimal scale is measured to reflect the rational distribution degree of the overall scale of the input-output factors [32].

Suppose there are $n$ decision-making units, in which each decision-making unit has $k$ input variables and $v$ output variables, $x_{1 i}, x_{2 i}, \ldots \ldots, x_{k i}$ and $y_{1 i}, y_{2 i}, \ldots \ldots, y_{v i},\left(x_{j i}>0, y_{w i}>0, j=1,2,3\right.$, $\ldots \ldots, k, w=1,2,3 \ldots \ldots v, i=1,2,3, \ldots \ldots n)$ and $\mu_{i}$ represents the weight vector of the input and output in each region. In the input-oriented BCC model, each decision-making unit $D M U_{j}$ has its corresponding efficiency evaluation index $\alpha$, and the optimal model of the input-output efficiency of this decision-making unit is as follows [31]:

$$
\left\{\begin{array}{l}
\min \alpha \\
\sum_{i=1}^{n} \mu_{i} x_{i} \leq \alpha x_{i 0} \\
\sum_{i=1}^{n} \mu_{i} y_{i} \geq \alpha x y_{i 0} \\
\sum_{i=1}^{n} \mu_{i}=1
\end{array}\right.
$$

In formula (4), $\mu_{i} \geq 0, i=1,2,3, \ldots \ldots n$.

\subsection{Variable Selection and Data Description}

\subsubsection{Samples and Data}

In 2008, the "Great tee" between the two sides of the strait was officially realized. The official launch of direct air transportation, direct maritime transportation, and direct mail have promoted the development and further development of tourism in strait cities. Therefore, this study selected 2008 as the starting point for data collection and established a tourism-related database for the West Coast of the Strait urban agglomeration between 2008 and 2017. Within the database, the efficiency of the tourism industry is regarded as the explained variable, and the intensity of tourism economic contact is regarded as the core explanatory variable. Additionally, the regional economic level, industrial 
structure, urbanization level, traffic development level and level of opening up to the outside world are selected as control variables in the model. The tourism-related data used in this study come from the "Statistical Almanac of Fujian Province", "Statistical Almanac of Zhejiang Province", "Almanac of Xiamen Special Economic Zone", "The statistical bulletin of national economic and social development of Fuzhou", "The statistical bulletin of national economic and social development of Yingtan", the CEIC database and others. The data processing software used in this study is Stata14.0.

\subsubsection{Definition of Variables}

(1) Explanatory variable: The intensity of tourism economic contact (TER). The tourism economic contact is mainly manifested as the mutual flow of tourism elements in space-including the tourists flow, tourism commodities, practitioners, and information, etc. In this study, the gravity correction model is used to measure the intensity of tourism economic contact between cities in the West Coast of the Strait urban agglomeration, and the intensity of tourism economic contact between each city and other cities is summed to obtain the intensity of tourism economic ties in the city group. The amount of tourism economic contact measured based on the gravity model has a clear regional boundary, and the amount of tourism economic contact as a measure index of the explanatory variable is helpful to better explore the influence of the tourism economic contact intensity on the efficiency of the tourism industry.

(2) Explained variable: The efficiency of tourism industry refers to the economic benefits that can obtain after applying certain costs, which reflects the internal relation and ratio relation between the input and output of tourism economic activities. In this study, data envelopment analysis (DEA) was used to measure the tourism industry efficiency of 20 cities in the West Coast of the Strait urban agglomeration between 2008 and 2017. From the perspective of economics, the factors of production mainly include capital factors, labor factors and land. The development of regional tourism is not restricted by land [33], so it is not included in this study. In terms of investment indicators, this study uses urban fixed-asset investment and the number of star-rated hotels as capital input variables from the perspective of capital factors. Direct investment in tourism infrastructure and the construction of tourist attractions are capital input factors related to regional tourism. However, due to the lack of these data in the domestic statistical almanac, urban fixed-asset investment is selected instead. Although urban fixed-asset investments are mainly used for the construction of urban infrastructure and the improvement of related main functions and the direct part of the investment in regional tourism is a small proportion, to a certain extent, the improvement of urban self-construction is also a very advantageous attraction in tourism. In addition, A-level scenic locations are an important part of tourism resources in tourism destinations and have a certain appeal to tourists. A-level scenic locations are not only an important factor reflecting the tourism reception capacity of a region but are also an important indicator of the region's investment in tourism capital [34].

From the perspective of labor factors, this study uses the number of employees in the tertiary industry as a measure of labor input. The number of tourism employees is an appropriate variable to measure labor input in the tourism industry, but these data are lacking in data sources, such as statistical yearbooks, in various regions; therefore, replacing them with the number of employees in the tertiary industry is reasonable. Due to the comprehensive characteristics of the tourism industry, it has a high degree of integration with other industries in the tertiary industry. To some extent, the number of employees in the tertiary industry includes both direct and indirect employees of the tourism industry [35]. From the perspective of output, this study selects the total number of domestic and foreign tourists and total tourist revenue as the output index. The total number of tourists and total tourist income are important criteria for the tourism industry to measure its economic output after inputting certain factors. Overall, this output index can reflect the development level of a region's tourism industry; if the total number of tourists and total tourist revenue are both greater, the development level of the regional tourism industry will be higher [36]. In summary, the input 
and output indicators of tourism industry efficiency selected in this study are scientifically based on their availability.

Control variables: (1) Regional economic level (REL): This index reflects the economic development of a region (e.g., development scale and speed) to some extent. If the level of economic development is higher, the tourism infrastructure will be more perfect, and the ability to provide tourism services to the public will be higher, which will have a certain impact on the development of tourism. The level of regional economic development is expressed in terms of per capita GDP. (2) Industrial structure (IS): Also known as the sectoral structure of the national economy, from the perspective of the three industries, it mainly refers to the internal relationship between the primary industry, the secondary industry, and the tertiary industry. The industrial structure has constantly altered the proportion to the primary industry, the secondary industry, and the tertiary industry. An industrial structure with a higher optimization level can play a certain role in promoting the healthy development of the tourism industry, and it will also play a certain role in improving the efficiency of the tourism industry [37]. Therefore, this study represents the industrial structure as the proportion of the output value of the tertiary industry to the total GDP. (3) Urbanization level (UL): It refers to the degree of urbanization reached in a region, reflecting the proportion of the population living in large, medium, and small towns in the total urban and rural population of a region, country, or the world. The urbanization level not only has an impact on the level and pattern of tourism consumption in the region, but also has a certain impact on the development of tourism enterprises [38]. In this study, the urbanization level is represented by the proportion of the urban population to the total population of the region at the end of the year. (4) The level of opening up to the outside world (DO): It refers to the degree to which a country or region's economy is open to the outside world under the condition of a market economy. It also indicates the degree of contact between a country or region and the outside world. The level of opening to the outside world represents advanced science, technology, management level and concept. Driven by the rapid development of Chinese inbound and outbound tourism, the degree of opening up to the outside world will have a profound impact on the development of the tourism industry [39]. (5) Traffic development level (TL): It refers to the development stage or development degree of a region's transportation at a certain time, taking some measurement indicators as the object and according to the corresponding evaluation indicators. Transportation infrastructure is one of the most important foundations and prerequisites for tourism development. Additionally, the degree of transportation convenience has a direct influence on tourism accessibility [40], which is not only conducive to the development of the tourism economy and enhances its potential, but also to the emergence of spatial spillover effects that can affect the tourism economic development of the surrounding areas. This study expresses the level of transportation development by highway mileage. Before performing regression analysis on the relevant data, this study conducted a descriptive statistical analysis of related variables to observe their distribution and discrete degree, as shown in Table 1. It can be found that the value of each variable is in the normal range, i.e., there are no outliers. In addition, this study performs a logarithmic treatment on some variables (i.e., the intensity of tourism economic contact, the level of opening up to the outside world and traffic development level) to avoid a large gap between the values of the variables. 
Table 1. Descriptive statistics of the variables.

\begin{tabular}{ccccccc}
\hline $\begin{array}{c}\text { Variable } \\
\text { Code }\end{array}$ & Variable Meaning & Sample Size & Mean & $\begin{array}{c}\text { Standard } \\
\text { Deviation }\end{array}$ & Maximum & Minimum \\
\hline TIE & $\begin{array}{c}\text { Efficiency of the tourism } \\
\text { industry }\end{array}$ & 200 & 0.732 & 0.230 & 1.000 & 0.252 \\
TER & Intensity of tourism economic & & & & & \\
contact & 200 & 5.187 & 1.474 & 8.204 & 0.125 \\
REL & Regional economic level & 200 & 4.415 & 3.062 & 19.360 & 0.972 \\
IS & $\begin{array}{c}\text { Industrial structure } \\
\text { Urbanization level }\end{array}$ & 200 & 38.760 & 6.558 & 57.800 & 26.400 \\
DL & Level of opening up to the & 200 & 43.160 & 18.43 & 89.100 & 17.120 \\
outside world & 200 & 10.210 & 1.183 & 13.620 & 7.427 \\
\hline
\end{tabular}

Source: Collation of this study.

\section{Analysis of Test Results}

\subsection{Model Settings}

To explore the relationship between tourism economic networks and the efficiency of the tourism industry, this study used the intensity of tourism economic contact as the explanatory variable and the efficiency of the tourism industry as the explained variable and examines the influence of the five control variables (regional economic level, industrial structure, urbanization level, the level of opening up to the outside world and the traffic development level). This study established the following model [41]:

$$
\begin{gathered}
\text { Performance }_{i, t+2}=\beta_{0}+\beta_{1} \text { Founder }_{i, t}+\beta_{2} \text { Economy }_{i, t}+\beta_{3} \text { Industry }_{i . t}+\beta_{4} \text { Urban }_{i, t}+\beta_{5} \text { Open }_{i, t} \\
+\beta_{6} \text { Transportaion }_{i, t}+\varepsilon_{i t}
\end{gathered}
$$

In the formula, Performance $e_{i, t+2}$ is the explained variable, which indicates the efficiency of the tourism industry of city $i$ in year $t+2$; Founder ${ }_{i, t}$ is the explanatory variable of this study, which indicates the intensity of tourism economy contact of city $i$ in year $t$; Economy $i_{i, t}$, Industryi.t, Urban $i_{i, t}$, Open ${ }_{i, t}$ and Transportaion $i, t$ are the control variables of the model, which represent regional economic level, industrial structure, urbanization level, level of opening up to the outside world and traffic development level, respectively; $\beta_{0}$ is the intercept term; $\beta_{1}-\beta_{6}$ are the parameters to be estimated; and $\varepsilon_{i t}$ is the disturbance term that contains all the factors affecting the efficiency of the tourism industry except the explanatory and control variables.

\subsection{Basic Model Test}

This study examined the impact of the intensity of tourism economic contact on the efficiency of the tourism industry. To ensure the robustness of the results, this study used a stepwise regression to estimate the mixed effect model. To investigate the possible nonlinear relationship between the intensity of tourism economic contact and the efficiency of the tourism industry, this study added the quadratic term of the intensity of tourism economic contact to the model. Table 2 shows the regression results of the relationship between the intensity of tourism economic contact and the efficiency of the tourism industry in the West Coast of the Strait urban agglomeration.

The impacts of the explanatory variable tourism economic contact intensity (TER) and its quadratic term $\left(\mathrm{TER}^{2}\right)$ on the efficiency of the tourism industry passed the significance test. Additionally, the coefficients of the primary and secondary terms of the tourism economic contact intensity are negative and positive, respectively, which indicate that the nonlinear relationship between the two is valid. The intensity of tourism economic contact has a U-shaped effect on the efficiency of the tourism industry, which means that before reaching the critical point, the efficiency of the tourism industry will be reduced with the strengthening of the intensity of tourism economic contact. When the critical point is exceeded, the efficiency of the tourism industry will continue to improve with the strengthening of the intensity of tourism economic contact. To more intuitively reflect the U-shaped impact of the 
economic contact intensity on the efficiency of the tourism industry, this study provides a U-shaped graph of the relationship between the intensity of tourism economic contact and the efficiency of the tourism industry (as shown in Figure 1). The data analysis results do not change with the gradual addition of the control variables, indicating that the analysis results are stable. The subsequent analysis in this study is based on the estimation results of model 6, which included all the variables.

Table 2. Basic model test.

\begin{tabular}{|c|c|c|c|c|c|c|}
\hline \multirow{2}{*}{ Variable } & \multicolumn{6}{|c|}{ TIE } \\
\hline & Model 1 & Model 2 & Model 2 & Model 4 & Model 5 & Model 6 \\
\hline TER & $\begin{array}{c}-0.111 \text { ** } \\
(0.02)\end{array}$ & $\begin{array}{c}-0.115^{* *} \\
(0.02)\end{array}$ & $-0.113^{* *}(0.03)$ & $-0.114^{* *}(0.04)$ & $-0.111^{* *}(0.03)$ & $-0.110^{* *}(0.04)$ \\
\hline TER $^{2}$ & $0.009 *(0.06)$ & $\begin{array}{c}0.011^{* *} \\
(0.04)\end{array}$ & $0.011^{* *}(0.03)$ & $0.011^{* *}(0.04)$ & $0.011^{* *}(0.02)$ & $0.011^{* *}(0.04)$ \\
\hline REL & & $\begin{array}{c}-0.015^{* * *} \\
(0.00)\end{array}$ & $-0.017^{* * *}(0.00)$ & $-0.022^{* * *}(0.00)$ & $-0.020^{* * *}(0.00)$ & $-0.021^{* * *}(0.00)$ \\
\hline IS & & & $0.001(0.13)$ & $0.001(0.24)$ & $0.001(0.11)$ & $0.001(0.14)$ \\
\hline UL & & & & $0.002 *(0.08)$ & $0.002(0.13)$ & $0.001(0.12)$ \\
\hline DO & & & & & $-0.010(0.70)$ & $-0.009(0.55)$ \\
\hline TL & & & & & & $-0.011(0.33)$ \\
\hline Constant & $\begin{array}{c}1.032 * * * \\
(0.00)\end{array}$ & $\begin{array}{c}1.085^{* * *} \\
(0.00)\end{array}$ & $1.031^{* * *}(0.00)$ & $0.982^{* * *}(0.00)$ & $1.068^{* * *}(0.00)$ & $1.161^{* * *}(0.00)$ \\
\hline $\mathbf{R}^{2}$ & 0.024 & 0.059 & 0.055 & 0.063 & 0.061 & 0.057 \\
\hline $\mathbf{F}$ & 3.463 & 5.126 & 3.886 & 3.692 & 3.149 & 2.703 \\
\hline$N$ & 200 & 200 & 200 & 200 & 200 & 200 \\
\hline
\end{tabular}

Note: ${ }^{* * *} p<0.01,{ }^{* *} p<0.05,{ }^{*} p<0.1, p$ statistics are in parentheses. Source: Collation of this study.

In terms of the control variables, the influence of the regional economic level (REL) on the efficiency of the tourism industry is negative $(p<0.01)$, which shows that the efficiency of the tourism industry will continue to decline with the improvement of the regional economic level. The $t$-value of the urbanization level (UL) on the efficiency of the tourism industry is $1.22(p<0.1)$. Considering that the sample size of this study is relatively small, the criteria for the level of significance can be appropriately relaxed. It can be considered that the positive effect of the urbanization level on the efficiency of the tourism industry is significant, which means that the efficiency of the tourism industry will also be enhanced with the improvement of the urbanization level. The impacts of the industrial structure (IS), the level of opening up to the outside world (DO) and the level of traffic development (TL) on the efficiency of the tourism industry do not pass the significance test, and there is not enough evidence to show that these three variables will have an impact on the efficiency of the tourism industry.

\subsection{U-Shaped Curve Analysis}

The above research results show that there is a U-shaped relationship between the intensity of tourism economic contact and the efficiency of the tourism industry under the condition of adding control variables, such as regional economic and urbanization levels(as shown in Figure 2).

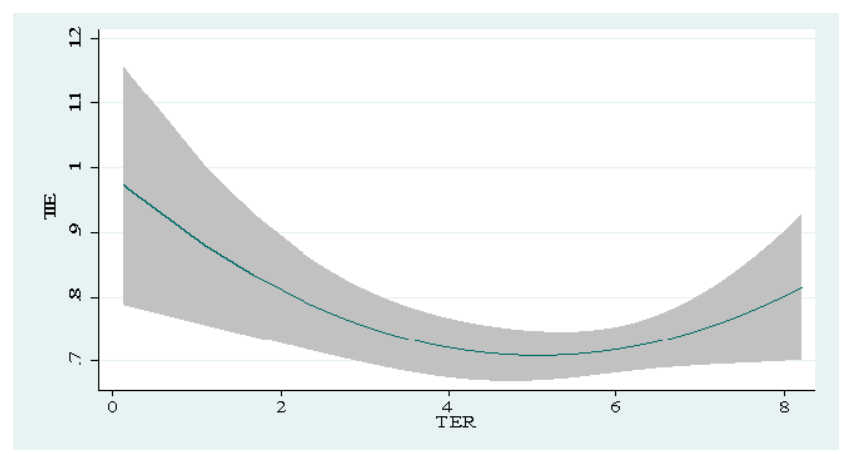

Figure 2. U-shaped graph of the influence of the tourism economic contact intensity on tourism industry efficiency. 
(1) The intensity of tourism economic contact has a U-shaped effect on the efficiency of the tourism industry, which means that in the initial stage, the efficiency of the tourism industry will decrease with the improvement of the intensity of tourism economic contact and that when the intensity of tourism economic contact reaches a certain level, the efficiency of the tourism industry will gradually increase with its improvement. The tourism economic contact in the region generally shows the stage characteristics. The tourism economic contact gradually strengthens, and its development gradually tends to mature [30]. In the initial stage, the intensity of tourism economic contact between cities is relatively weak, and the immature tourism cooperation model leads to the outflow of tourism elements in the region, which will result in a siphon negative effect. The efficiency of the tourism industry increases with the enhancement of the tourism economic contact intensity. With the gradual maturity of the tourism cooperation model among cities in the region, the phenomenon of the return of tourism elements will occur, which will produce a siphon positive effect [42], and the efficiency of the tourism industry will increase with the enhancement of the intensity of tourism economic contact.

(2) The research results show that the regional economic level harmed the efficiency of the tourism industry, while the urbanization level had a positive effect on the efficiency of the tourism industry. When the economic resources and policy support in the region are more inclined to other industries [43], and the propensity towards the tourism industry is low, the regional economic level may negatively affect the efficiency of the tourism industry. A higher urbanization level is, to some extent, helpful to stimulate tourists' motivation to travel, promote their travel decisions, increase regional tourism revenue and improve the efficiency of the tourism industry.

(3) The research results showed that the industrial structure, the level of opening up to the outside world, and the level of transportation development had no effect on the efficiency of the tourism industry. Although a high-level industrial structure is beneficial to the improvement of tourism product structures and service forms, when the regional industrial structure reaches a certain level, its influence on the efficiency of the tourism industry is not significant. A higher level of opening up to the outside world is not only beneficial to the improvement of tourism industry efficiency but will also have a reverse effect on the development of tourism industry efficiency [44]. A positive force and negative effect are output simultaneously, and the effect on the efficiency of the tourism industry is not significant. Areas with a higher level of transportation development are beneficial to introduce more tourist flow, but a high level of transportation development will help reduce the number of overnight visitors to some extent, which has both advantages and disadvantages and has no significant influence on the efficiency of the tourism industry.

\subsection{Robustness Test}

Regions with highly efficient tourism industries in the current period may have closer ties. As a result, there is an endogenous problem in estimating the influence of the intensity of tourism economic contact on the efficiency of the tourism industry. To prevent possible errors in the estimation results caused by the endogenous problem, this study adopted the dynamic panel estimation method and systematic GMM (e.g., Generalized Method of Moments) estimation to investigate the influence of the intensity of tourism economic connection on the efficiency of the tourism industry. System GMM estimation model in the measuring dynamic panel data has strong effectiveness, if the difference estimation and level estimation into a system and then to estimate at the same time, the difference equation used in tool variables remains level lag, the horizontal equation you can use the corresponding variable difference of lag as a proxy variable. The estimation results are shown in Table 3. The Hansen test is used to examine the instrumental variables for transitional identification problems and to determine whether the instrumental variables set is reasonable. If the P value is greater than 0.1 in the Hansen test results, then the null hypothesis is accepted, and the choice of instrumental variables is reasonable [45]. From the results of the Hansen test in Table 3, the P value is greater than 0.1, indicating that the setting of the instrument variables in the model is reasonable. This study uses the 
Arellano-Bond test statistics to test whether the error term of the model is related to a second-order sequence. Because GMM is valid regardless of whether there is a first-order sequence correlation in the residual term after the difference, the GMM estimation cannot have second-order sequence correlation. In the results of the Arellano-Bond test presented in Table 3, the P values of AR (1) and AR (2) are all greater than 0.2 , and the null hypothesis cannot be rejected; thus, there is no first- and second-order autocorrelation. The above tests indicate that the estimation results of SYS-GMM in this section are valid.

Table 3. System GMM estimation results.

\begin{tabular}{cc}
\hline Variable & TIE \\
\hline TER & $-0.120^{* * *}(0.00)$ \\
TER $^{2}$ & $0.008^{* * *}(0.00)$ \\
REL & $-0.004(0.14)$ \\
IS & $-0.000(0.46)$ \\
UL & $0.001^{* *}(0.03)$ \\
DO & $0.017^{* * *}(0.00)$ \\
TL & $0.007(0.21)$ \\
N & 180 \\
AR(1) & 0.401 \\
AR(2) & 0.132 \\
Hansen & $17.220(0.102)$
\end{tabular}

Note: $p$ statistics are in parentheses, ${ }^{* * *} p<0.01{ }^{* *} p<0.05,^{*} p<0.1$. AR (1) and AR (2) represent the $p$ values of the Arellano-Bond test statistic. The error term used to test the model is a second-order sequence correlation. The Hansen value is used to test whether the setting of the tool variable is reasonable. Source: Collated by this study.

The test results, presented in Table 3, show that the effects of the primary and quadratic terms of the tourism economic contact intensity on the efficiency of the tourism industry have both passed at a $1 \%$ significance level. The estimated coefficients of the primary and quadratic terms are negative and positive, which indicate that the influence of the tourism economic contact intensity on the efficiency of the tourism industry shows the characteristic U-shaped effect, which further verifies the conclusion of this study. Therefore, the U-shaped influence of the tourism economic linkage intensity on the efficiency of the tourism industry is sound.

\section{Results and Discussion}

\subsection{Conclusions and Discussion}

This study used the urban clusters on the West Coast of the Strait as an example and analyzes the effect of the tourism economic contact intensity on the efficiency of the tourism industry by constructing a mixed effect model. Additionally, the influence of the five control variables (regional economic level, industrial structure, urbanization level, opening up to the outside world and traffic development level) on the efficiency of the tourism industry is explored.

Between 2008 and 2017, the intensity of the tourism economic contact in the West Coast of the Strait urban agglomeration has a U-shaped effect on the efficiency of the tourism industry. This result means that before reaching the threshold, the efficiency of the tourism industry will be reduced with an increase in the tourism economic contact intensity; after reaching the threshold, the tourism industry efficiency will increase with an increase in the intensity of tourism economic contact intensity between the cities in the West Coast of the Strait urban agglomeration. The two sides of the strait officially entered the era of "Great tee" from 2008. Since then, the tourism interconnectedness of the city clusters across the strait has been significantly improved, and its tourism economic cooperation and exchanges have gradually developed in an all-round way, and its tourism advantages have been continuously exerted. Considering the heterogeneity of resources, the short distance between cities and the guiding power of policies, the regional urban system is a combination of a centripetal and 
centrifugal force composed of external economies and noneconomies. Additionally, the imbalance of these two forces will lead to the siphon effect of the central city on the surrounding cities. The siphon effect means that the economic developments of the urban clusters on the West Coast of the Strait remain unbalanced, the degree of the regional industry correlation is not high, the linkage is weak, and the central city's radiation capacity is weak [46]. At the beginning of the realization of the "Great tee", regional tourism cooperation is still in its infancy, tourism economic contact among cities is weak, and the tourism cooperation model is not perfect. The high-quality tourism elements and resources in the region will appear as counter-current phenomena [47]. This better economic development areas will lead to unbalance of tourism elements between cities in the region, such as weak interactivity, low optimization of tourism resource allocation, and slow development of tourism. These effects will have a negative impact on the development of the tourism industry. However, with the further development of the "Great tee", the economic ties between the cities of on the West Coast of the Strait have gradually become more open, the links between them have gradually strengthened [48]. As regional tourism cooperation has improved, the economic ties between regional cities have reached a stable level, the tourism industry cooperation model has reached maturity. Moreover, high-quality tourism resources and factors will return, regional cities will absorb the tourism resources and elements of the low-level economic development area, tourism interactivity will be enhanced, and the input and output of tourism elements in the region will be gradually stabilized [49]. The overall allocation of the tourism resource elements will be optimized to promote the rapid and efficient development of the tourism industry in the region.

(1) In the urban clusters on the West Coast of the Strait between 2008 and 2017, the regional economic levels have had a negative impact on the efficiency of the tourism industry, which indicates that when a regional economic level gradually improves, the efficiency of the tourism industry will tend to continue to decline. Previous studies have shown that the level of economic development will positively affect the efficiency of the tourism industry [50]. However, this study found that because of the existence of competition between different industries in the region (this competition is mainly reflected in economic resources and policy support), when financial support and policy support are more biased towards other industries, the level of economic development will hurt the efficiency of the tourism industry. The effect of the urbanization level on the efficiency of the tourism industry tends to be positive, which indicates that when the urbanization level improves, the efficiency of the tourism industry will gradually increase. A high level of urbanization means that urbanization is widely covered in terms of economic level, lifestyle and population distribution, which leads to a large influx of capital, high-tech and population. These factors can not only lay a solid foundation for the region to improve tourism infrastructure construction and tourism service systems and innovative tourism product systems, but also reflect the stronger consumption capacity of residents and tourists [51], which are the basis of tourism development and will promote the efficiency of the tourism industry to some extent.

(2) In the urban clusters on the West Coast of the Strait between 2008 and 2017, the industrial structure, the level of opening up to the outside world, and the level of traffic development have no significant impact on the efficiency of the tourism industry. These findings also mean that when the regional industrial structure, the level of opening up to the outside world and the level of traffic development have a change in trend or intensity, the changes in the efficiency of the tourism industry they caused fail to pass the significance test. To some extent, a high level industrial structure will lead to an inflow of external tourism supply resources and an outflow of local tourists [44], which will weaken the positive influence of the improvement and innovation of tourism product and service systems; thus, it has no significant impact on the efficiency of the tourism industry. In regions with a high level of opening to the outside world, people gather more and flow more frequently, which not only helps to improve the operational saturation of regional tourism reception facilities, but also helps the tourism industry to break through the traditional forms of products and services to innovate and enhance the retention of tourists. 
However, a high level of opening up to the outside world also means that a certain amount of external tourism supply resources will flow into the region, which will have a certain impact on the development of regional tourism. Therefore, its impact on the efficiency of the tourism industry is not significant. The level of traffic development will reduce the number of overnight visitors while expanding regional passenger flow to balance the two, which has no significant impact on the efficiency of the tourism industry.

\subsection{Theoretical Contribution}

Based on the panel data of the urban clusters on the West Coast of the Strait, this study constructed an econometric model to explore and find that the intensity of tourism economic contact has a nonlinear effect on the efficiency of the tourism industry. Previous studies on tourism economic contact have primarily focused on the impact of the spatial structure, patterns, characteristic differences, and transportation [21,52], and explored the influencing factors and forward effects of tourism economic contact. There are few related studies on the backward impact of tourism economic contact on tourism. This study can help enrich the relevant studies on the backward effect of tourism economic contact. Additionally, studies have shown that the strengthening of regional tourism cooperation is conducive to the further optimization of the allocation of tourism resources. They have also shown that these factors enhance the overall balanced development of regional tourism, help avoid the emergence of vicious competition problems, and promote the high-quality development of the tourism industry [53], which also reflects that there is a certain relationship between tourism economic contact and the efficiency of the tourism industry. However, there is no research on the direct effect of the relationship between tourism economic contact and the efficiency of the tourism industry. This study explores the relationship between the two from a new perspective, which is expected to provide theoretical guidance for promoting the development of tourism.

In addition to the influence of the regional economic level, tourism resource endowment, urbanization level and other factors on the efficiency of the tourism industry [39,54], this study found that the intensity of tourism economic contact is an important factor that affects this efficiency. Moreover, a change in tourism industry efficiency is not always a rise or a decline [55]. This study found that the intensity of tourism economic contact has a U-shaped effect on the efficiency of the tourism industry. This finding can be explained based on the principle of the siphon effect, which is also called the siphon phenomenon. Previous studies have shown that the relationship between regional economic development shows a nonlinear relationship when there is continuous close regional economic contact [56], which also indirectly shows that the flow of factors between regions are not always one-way, and will have different effects on the development of their industries. The U-shaped effect of the intensity of tourism economic contact on the efficiency of the tourism industry is mainly due to the change from the negative to the positive effect of the siphon effect.

\subsection{Research Recommendations}

Based on the above analysis, this study posits the following suggestions for the development of the tourism industry in the West Coast of the Strait urban agglomeration: (1) To give full play to the role of the intensity of tourism economic contact. After the realization of the "Great tee", direct air transportation, direct sea transportation and direct mail across the Straits have strengthened the economic exchanges between the strait city clusters, which has laid a certain foundation for the tourism cooperation and exchange of the strait city group. Taking that as an example, first, we should strengthen the interaction of tourism between cities in the region to form efficient tourism flow routes between regions. Moreover, the roles and responsibilities of each city in tourism cooperation should be clearly defined to promote the optimization of the allocation of tourism resources among regions to improve the efficiency of the regional tourism industry. Clear definitions of the roles and responsibilities of each city in tourism cooperation are essential for the development of urban tourism in the region, especially for cities with a low overall development level. Second, the tourism cooperation mechanism 
of the city group in the West Coast of the Strait urban agglomeration should be improved, and the cooperation between the city group and surrounding areas should be strengthened. To form a tourism area with unimpeded information, people, and resource flow, it should complement and interact with the surrounding areas. (2) The efficiency of the tourism industry is affected by many factors, and the regional economic and urbanization levels will have an impact. Thus, when developing a local economy, each city in the urban agglomeration should consider increasing its funding and policy support for the tourism industry. Concurrently, the region should enhance its urbanization level, accelerate the construction of new towns, and continuously promote the optimization and development of the tourism industry structure to improve the efficiency of the tourism industry in the West Coast of the Strait urban agglomeration.

\subsection{Research Limitations and Future Prospects}

This study explores the nonlinear effect of the strength of tourism economic contact on the efficiency of the tourism industry, but it has the following limitations: (1) This study uses the urban clusters on the West Coast of the Strait as the case. Due to the difficulty in obtaining small-scale data, this study uses the city area as the research unit, making the research scale relatively macro. The intensity of tourism economic contact has a U-shaped effect on the efficiency of the tourism industry, and future research can further explore the changing trend of this effect on another type of classification. (2) The tourism economic development of the city groups in the West Coast of the Strait urban agglomeration is at a relatively high level in the whole country, and the tourism economic space between the cities is relatively perfect. Therefore, future research may try to further compare it with other city groups or consider joining the tourism information flow to further explore the role of mutual influence between tourism industry efficiency, tourism economy, and tourism information flow.

Author Contributions: Data curation, Y.L. and C.-H.L.; Funding acquisition, Y.L.; Methodology, W.R.; Resources, Y.L.; Software, R.L.; Writing—original draft, R.L. and W.R.; Writing-review and editing, C.-H.L. All authors have read and agreed to the published version of the manuscript.

Funding: National Social Science Foundation of China: No. 17BGL114.

Conflicts of Interest: The authors declare no conflict of interest.

\section{References}

1. Kuzmenko, A.; Kuznetsova, O.; Kuleeva, I.; Plotnikova, I. The Importance of Inter-Territorial Tourism Cooperation in the World and the Role of This Phenomenon in the Strategic Management of Tourism in the Russian Federation. Adv. Econ. Bus. Manag. Res. 2018, 47, 364-366.

2. China Tourism Academy. Basic Situation of the Tourism Market in 2019. 2020. Available online: http: //www.ctaweb.org/html/2020-3/2020-3-10-16-48-64712.html (accessed on 23 May 2020).

3. Li, S.J.; Chen, J. The Cooperation-Competition Model of Regional Tourism Cities of Shandong Based Niche Theory. Econ. Geogr. 2014, 9, 179-185.

4. Hall, C.M.; Page, S.J. The Geography of Tourism and Recreation: Environment, Place and Space; Routledge: London, UK, 2014.

5. An, H.; Xiao, C.; Ding, M. The Spatial Pattern of Ski Areas and its Driving Factors in China: A Strategy for Healthy Development of the Ski Industry. Sustainability 2019, 11, 3138. [CrossRef]

6. Liu, C.M.; Zhang, R.Y.; Wang, M. Measurement and Prediction of Regional Tourism. Sustainability: An Analysis of the Yangtze River Economic Zone, China. Sustainability 2018, 10, 1321. [CrossRef]

7. Zhang, H.; Xia, M. A Study on the Spatial Structure of Tourism in Anhui Province-from the Perspective of the Relationship between Tourism Cnter Degree and Tourism Economy. Econ. Geogr. 2011, 12, 166-171.

8. Shen, J.H.; Lu, Y.Q.; Zhou, Y.C.; Yin, Y.M. Spatial Linkage Pattern of Tourism Economy in Wanjiang Urban Agglomeration. Resour. Environ. Yangtze River Basin 2012, 21, 1434-1441.

9. Liu, W.P.; Dong, C.L.; Chen, W.J. Mapping and Quantifying Spatial and Temporal Dynamics and Bundles of Travel Flows of Residents Visiting Urban Parks. Sustainability 2017, 9, 1296. [CrossRef] 
10. Ye, M.; Wang, Z.F. Coupling and Coordination Analysis of the Linkage between Transportation Accessibility and Tourism Economy in Wuling Mountain Area. Econ. Geogr. 2017, 37, 213-219.

11. Bian, X.H. Research on the Spatial Structure of Urban Tourism. Geogr. Inf. Sci. 2003, 19, 105-108.

12. Zou, Y.G.; Zhu, Y.; He, Y.M. Spatial Structure of Tourism Economy and Evolution of Cooperation Pattern in the Economic Zone on the West Side of the Straits. Econ. Geogr. 2018, 38, 228-235.

13. Qi, R.; Xu, D.R. An Analysis of the Influence of Mowan Railway on the Potential of Tourism Economic Connection of Cities Along the Line. World Geogr. Res. 2018, 27, 42-51.

14. Song, M.; Li, H. Estimating the Efficiency of a Sustainable Chinese Tourism Industry Using Bootstrap Technology Rectification. Technol. Forecast. Soc. Chang. 2019, 143, 45-54. [CrossRef]

15. Christaller, W. Some Considerations of Tourism Location in Europe: The Peripheral Region underdeveloped Countries-recreation Areas. Reg. Sci. 1964, 12, 95-105. [CrossRef]

16. Zurick, D.N. Adventure Travel and Sustainable Tourism in the Peripheral Economy of Nepal. Ann. Assoc. Am. Geogr. 1992, 82, 608-628. [CrossRef]

17. Roberto, C.; Tiziana, C. The Economic Resilience of Tourism Industry in Italy: What the "Great-Recession" Data Show. Tour. Manag. Perspect. 2015, 16, 346-356.

18. Garza, G. Global Economy, Metropolitan Dynamics and Urban Policies in Mexico. Cities 1999, 16, 149-170. [CrossRef]

19. Dianne, D. Destination Place Planning and Design. Ann. Tour. Res. 1999, 4, 772-791.

20. Cao, F.D.; Wu, J.; Xu, M.; Xue, X.W. Measurement and Analysis of Tourism Economic Spatial Connections in the One-day Tour of the Yangtze River Delta City. Hum. Geogr. 2010, 4, 109-114.

21. Yang, L.H.; Liu, N.; Bai, C.L. The Spatial Structure of the Tourism Economy in Beijing-Tianjin-Hebei-Xiongan Region. Geogr. Sci. 2018, 38, 394-401.

22. Li, S.M.; Shum, Y.M. Impacts of the National Trunk Highway System on Accessibility in China. J. Transp. Geogr. 2001, 9, 39-48. [CrossRef]

23. Ni, W.Q.; Liao, M.L. The Spatial Impact of High-speed Railway on the Tourism Economic Contact of Chinese Capital Cities. China Popul. Res. Environ. 2018, 28, 160-168.

24. Jiang, X.J. Resource Restructuring and Service Industry Growth in Highly Interconnected Society. Econ. Res. 2017, 3, 6-19.

25. Chen, C.F.; Chiou-Wei, S.Z. Tourism Expansion, Tourism Uncertainty and Economic Growth: New Evidence from Taiwan and Korea. Tour. Manag. 2009, 30, 812-818. [CrossRef]

26. Sarrión-Gavilán, M.D.; Benítez-Márquez, M.D.; Mora-Rangel, E.O. Spatial Distribution of Tourism Supply in Andalusia. Tour. Manag. Perspect. 2015, 15, 29-45. [CrossRef]

27. Liu, J.; Lu, J.; Liu, N. Spatial-temporal Evolution, Influencing Factors and Formation Mechanism of Tourism Industry Efficiency in China's Coastal Areas based on DEA-Malmquist Model. Resour. Sci. 2015, 37, 2381-2393.

28. Fagence, M. Regional Tourism Cooperation. Ann. Tour. Res. 1996, 23, 717-720. [CrossRef]

29. Liu, X.M.; Hu, Y.X.H.; Liu, N.Y. Analysis of the Tourism Economic Linkage of Beijing-Tianjin-Hebei Urban Agglomeration-Based on Improved Gravity Model. China Circ. Econ. 2020, 34, 121-128.

30. Yu, H.Y.; Li, Q.Y.; Mei, L.; Liu, J.S. Research on the Spatial Structure and Spatial Development Model of Urban Tourism Economic Connection in Heilongjiang Province from the Perspective of Social Network. Geogr. Sci. 2015, 35, 1429-1436.

31. Dyckhoff, H.; Allen, K. Measuring Ecological Efficiency with Data Envelopment Analysis (DEA). Eur. J. Oper. Res. 2001, 132, 312-325. [CrossRef]

32. Zofio, J.L. Malmquist Productivity Index Decompositions: A Unifying Framework. Appl. Econ. 2007, 39, 2371-2387. [CrossRef]

33. Ma, X.L.; Ba, J.G. Evaluation of Tourism Efficiency of Major Cities in China based on Data Envelopment Analysis. Resour. Sci. 2010, 32, 88-97.

34. Wang, Z.F.; Yang, X. Research on the Evaluation of the Efficiency of Tourism Industry in Central Urban Agglomeration Based on DEA-Malmquist Model. Tour. Sci. 2018, 32, 31-42.

35. Wei, L.; Bu, W.; Wang, Z.L. Has the Opening of the High-speed Railway Promoted the Efficiency of the Tourism Industry?-An Empirical Analysis Based on the Chinese Provincial Level. Econ. Manag. 2018, 40, 74-92.

36. Wang, K.; Huang, Z.F.; Tao, Y.G.; Fang, Y.L. Study on Spatial Characteristics and Spillover Effects of Urban Tourism Efficiency: A Case of Yangtze River Delta. Econ. Geogr. 2013, 33, 161-167. 
37. Su, J.J.; Sun, G.N.; Wang, L.F. An Analysis of the Correlation Driven by China's Tourism Industry to the Tertiary Industry since 1982. Adv. Geogr. 2011, 30, 1047-1055.

38. Zhang, H.Q.; Luo, J.M.; Xiao, Q.; Guillet, B.D. The Impact of Urbanization on Hotel Development: Evidence from Guangdong Province in China. Int. J. Hosp. Manag. 2013, 34, 92-98. [CrossRef]

39. Liu, J.G.; Liu, Y. Pattern and Influencing Factors of Total Factor Productivity of Urban Tourism in Hangzhou from 2006 to 2013. Econ. Geogr. 2015, 35, 190-197.

40. Shen, P.P.; Zhou, N.X.; Zhang, Y.X.; Wang, K.; Li, Z.J. Spatial-temporal Evolution and Influencing Factors of Tourism Industry Efficiency in Jiangsu Province based on the Second Decomposition Model of DEA-Malmquist Index. Res. Environ. Yangtze River Basin 2018, 27, 53-62.

41. Yang, C.; He, X.G.; Xu, R.C. Founder Generation-Kin Modes and Business Performance: An Empirical Study Based on Chinese Family Listed Companies. Econ. Manag. 2018, 40, 17-37.

42. Shi, Q.B.; Xie, Y.S.; Han, Z.L.; Liu, T.B.; Liu, G.C.; Du, P. Spatial Structure and Development Model of Tourism Economic Connection among Northeast Cities. Econ. Geogr. 2018, 38, 211-219.

43. Yang, S.S.; Deng, W.J. A Ccomparative Study on the Relationship between Tourism Economy and High-speed Railway Transportation Network Pattern in Urban Agglomerations in China. Stat. Decis. 2019, 35, 135-138.

44. Zhang, P.; Yu, W.; Xu, D.F. Research on Provincial Tourism Efficiency Measurement and Influencing Factors in China-Based on SFA and Spatial Durbin Model Analysis. Macroecon. Res. 2014, 6, 80-85.

45. Hansen, B.E. Threshold Effects in Non-Dynamic Panels: Estimation, Testing, and Inference. J. Econom. 1999, 93, 345-368. [CrossRef]

46. Zhu, J.; Li, Q.; Cai, X.X. Evaluation of Urban Development based on Economic Level Indicators-A Case Study of 20 Cities in the Economic Zone on the West Coast of the Strait Urban Agglomeration. Econ. Issues 2017, 12, 120-123.

47. Zou, D.L.; Jiang, T.Y.; Liu, C.J.; Xu, M. Study on the Spatial Linkage of Tourism Economy in the Yangtze River Delta. East China Econ. Manag. 2014, 28, 65-70.

48. Ma, Y.; Xue, F.; Sun, W.; Li, Y. Analysis of Urban Network Characteristics in the Economic Zone on the West Side of the Straits-Based on the Perspective of Functional Networks and Innovation Network. Geogr. Res. 2019, 38, 3010-3024.

49. Wang, D.G.; Niu, Y.; Qian, J. Evolution and Optimization of China's Urban Tourism Spatial Structure: A High Speed Rail Perspective. Tour. Manag. 2018, 64, 218-232. [CrossRef]

50. Li, K.X.; Jin, M.; Shi, W. Tourism as an Important Impetus to Promoting Economic Growth: A Critical Review. Tour. Manag. Perspect. 2018, 26, 135-142. [CrossRef]

51. Yu, H. Spatial Distribution of Comprehensive Urbanization Level in Anhui Province. Procedia Comput. Sci. 2018, 131, 401-408.

52. Skerritt, D.; Huybers, T. The Effect of International Tourism on Economic Development: An Empirical Analysis. Asia Pac. J. Tour. Res. 2005, 10, 23-43. [CrossRef]

53. Zhang, H.Q.; Tian, X.H.; Wang, L.L. The Cooperation-competition Development in Regional Tourism Industry: Based on the Comparative Analysis of City Tourism Competitiveness between Pearl River Delta and Yangtze River Delta. Econ. Geogr. 2010, 5, 871-875.

54. Onetiu, A.N.; Predonu, A.M. Economic and Social Efficiency of Tourism. Procedia Soc. Behav. Sci. 2013, 92, 648-651. [CrossRef]

55. Katircioglu, S. Tourism, Trade and Growth: The Case of Cyprus. Appl. Econ. 2009, 41, 2741-2750. [CrossRef]

56. Liu, H.; Ma, L. The Spillover Effect of Economic Development Imbalance in Beijing-Tianjin-Hebei Region from 1992 to 2013. Explor. Econ. Probl. 2016, 11, 59-66.

(C) 2020 by the authors. Licensee MDPI, Basel, Switzerland. This article is an open access article distributed under the terms and conditions of the Creative Commons Attribution (CC BY) license (http://creativecommons.org/licenses/by/4.0/). 